\title{
ANALÍTICA DA CIDADANIA E O SERVIÇO SOCIAL NA ATUALIDADE: DA TEORIA À PRÁTICA
}

\begin{abstract}
Resumo: Embora cientes da importância de que se revestem as abordagens teóricas da cidadania, que colocam a ênfase no processo evolutivo de consolidação da cidadania que se inicia nos direitos civis $e$ «termina» nos direitos sociais, no presente ensaio, pretendemos explanar as abordagens que, embora não descurando a perspetiva anterior, defendem a necessidade do debate sobre a cidadania transitar para um nível mais concreto, de modo a considerar as estratégias facilitadoras da concretização efetiva dos direitos, estratégias essas, essenciais para um Serviço Social que se deseja promotor da cidadania ativa.
\end{abstract}

Manuel Menezes

Palavras-chave: Serviço Social; Cidadania Ativa; Neoliberalismo; Empowerment.

\begin{abstract}
Although conscious of the importance revealed by the theoretical approaches to citizenship, that put the emphasis on the evolutionary process of consolidation of citizenship, i.e., a process that begins in the civil rights and «ends» in the social rights. In this paper, our main aim is to analyze the approaches that, although recognizing the importance of the previous perspective, sustain the need of the debate on the citizenship to transit for a more concrete level. That is, we want to take into consideration those strategies that can contribute to the effective materialization of rights, strategies those, essential for a social work that can lead to an active citizenship.
\end{abstract}

Keywords: Social Work; Active Citizenship; Neoliberalism; Empowerment.

\footnotetext{
${ }^{1}$ Doutor em Ciências da Comunicação (especialidade de Comunicação e Cultura) pela Faculdade de Ciências Sociais e Humanas da Universidade Nova de Lisboa. Nos últimos 17 anos, exerceu as funções de docente nas áreas de Serviço Social e Ciências Sociais no ensino superior. Atualmente é professor das áreas de Comunicação e Serviço Social no ISMT, e de Serviço Social na Universidade Católica Portuguesa Polo de Viseu.
} 


\section{NOTA INTRODUTÓRIA}

Embora cônscios de que, a interligação das questões da cidadania com o desempenho profissional não é uma tarefa fácil, pensamos que a mesma se pode transformar num empreendimento aliciante dada a pertinência que assume na atualidade. Se ao referido acrescentarmos que, cada vez mais, na atualidade, por um lado, se levantam acesos debates em torno da cidadania e, por outro, ao nível da prática, em nossa opinião, os assistentes sociais encontram, possivelmente, sérias dificuldades na promoção da mesma, facilmente se aceita o interesse que pessoalmente devotamos ao estudo das questões que envolvem esta temática. Paralelamente, sabendo que existe uma relação profunda entre as possibilidades de agir do assistente social e a forma como as condições concretas da experiência são reguladas, pensamos que o desenvolvimento destas exegeses permite não só uma clarificação do imediato com que os profissionais trabalham, mas também a captação do mediato do fazer profissional, facilitando a compreensão da complexidade labiríntica de mediações que envolve a nossa profissão e, em consequência, o sentido que a mesma adquire num dado momento histórico.

Assim, em nossa opinião, a análise das diferentes possibilidades de apreensão da problemática da cidadania, poder-se-á constituir, em última instância, como um via clarificadora do papel que é atribuído à esfera profissional na atualidade, propugnando, em consequência, uma atuação em conformidade com o esperado ou, dentro das possibilidades da experiência, a ação de acordo com a urgência que sentimos em influenciar essas mesmas condições concretas. Por último, não descurando, igualmente, a atividade profissional que desenvolvemos e, estando conscientes da mutabilidade inerente ao concreto vivenciado, este tipo de análise é importante, porquanto, se constitui como uma via facilitadora para a manutenção da adequação à experiência dos conhecimentos que quotidianamente transmitimos aos discentes com que trabalhamos.

Destarte, na presente reflexão, procurar-se-á explanar a importância que a análise da perspetiva mais dinâmica da cidadania assume, para a compreensão da ação que os profissionais de serviço social desenvolvem em interconexão com os «cidadãos» que ocorrem aos serviços.

\section{CONDIÇÕES CONCRETAS DA EXPERIÊNCIA}

A análise da teoria da cidadania que toma como pano de fundo essencialmente a perspetiva marsheliana (T. H. Marshall, 1950), embora importante, não é, segundo alguns autores contemporâneos, suficiente para apreender a complexidade que envolve o conceito de cidadania. Isto 
é, a insuficiência da perspetiva marsheliana para a apreensão da complexidade que envolve o conceito de cidadania, conduz à necessidade de reequacionar novas vias de análise que tomem em atenção, não só, o direito na sua vertente formal, mas também na sua efetivação concreta.

Assim sendo, é urgente o questionamento sobre as diferenças que existem entre a teoria e a prática, i.e., até que ponto, na passagem da esfera privada para a pública as igualdades estão asseguradas, que percentagem da população tem acesso aos direitos consagrados na esfera pública, ou melhor, até que ponto a atual esfera pública é ou não um sinal clarividente de contradição entre os direitos retoricamente defendidos e praticamente não efetivados ${ }^{2}$. Por outras palavras, é necessário que o debate em volta desta temática, transite, de um nível abstrato, que não toma em atenção a contextualização dos direitos, para um outro, onde se desenvolva uma reflexão sobre as estratégias que possivelmente facilitarão a concretização efetiva dos direitos.

Paralelamente, deve ser realçada a necessidade de publicitar as desigualdades existentes na sociedade civil, para que, a conceção linear que tem predominado, possa ser substituída por um «ideal de equidade». É então necessário a constituição de espaços públicos onde as «[...] diferenças podem ser expressadas e representadas numa negociação possível; espaços nos quais valores circulam, argumentos se articulam e opiniões se formam; e nos quais, sobretudo, a dimensão ética da vida social se pode constituir em uma moralidade pública através da convivência democrática com as diferenças e os conflitos que elas carregam e que, exigem, por isso mesmo, de cada um, a cada momento, o exercício dessa capacidade propriamente moral de discernimento entre justo e injusto [...]» (Teles, 1994: 92).

Tendo em atenção o referido, será necessário analisar, por exemplo, a questão do acesso aos direitos, acesso esse, em termos reais por contraposição ao ideal que se explicita pela definição constitucional ou melhor dizendo direitos universais (Jenson, 1996). No caso concreto do serviço social é imprescindível uma reflexão permanente no que diz respeito ao conteúdo da prática que é desenvolvida pelos profissionais, repensando-a, tanto, na ótica da cidadania daqueles que já a possuem como é que pode ser complexificada - como, daqueles que embora simbolicamente sejam considerados cidadãos na realidade não o são como é que a podem obter.

$\mathrm{O}$ enunciado supra justifica-se, porque ao analisarmos a realidade que nos envolve constatamos que por um lado, estamos em presença de um

\footnotetext{
2 De acordo com Aldaiza Sposati, encontramo-nos face a uma sociedade virtual no que diz respeito à concretização dos direitos constitucionais. Fala-se, escreve-se, mas não se cumpre (1997: 10).
} 
forte desenvolvimento do mercado à escala planetária e, por outro, assistimos gradativamente à diminuição da «força» do Estado, tanto ao nível da regulação da produção, como ao nível da reprodução social.

Explicitando, a partir de finais da década de 60, as economias capitalistas centrais (e por influência as periféricas e semiperiféricas), deparam-se com uma crise sem precedentes, nomeadamente o aumento alucinante do desemprego, a agudização dos conflitos laborais, o enfraquecimento e precarização das relações salariais em paralelo com o recuo na concessão de direitos sociais anteriormente adquiridos.

No que diz respeito, por exemplo ao trabalho, sabendo, por um lado, que o mesmo se constitui como um dos meios principais de reconhecimento e de integração na sociedade e, por outro, que o número de excluídos do mercado de trabalho é cada vez maior, é urgente que façamos uma reflexão sobre a sociedade que desejamos «construir».

Para clarificar esta ideia, pensamos ser importante recorrer ao contributo de Robert Castel. Segundo este autor, «hoje em dia todas as situações sociais problematizadas exprimem um modo particular de dissociação do laço social», que ele denomina de «desafiliação social». Esta, por sua vez, vai resultar de dois processos, nomeadamente «[...] um processo de não integração pelo trabalho (no mundo do trabalho) e um processo de não inserção nas redes próximas de sociabilidade (familiar e social)» (Castel, apud Queloz, 1994: 156).

Deste modo e, não descurando o anteriormente referido relativamente ao trabalho, verifica-se que, hoje em dia, devido ao desenvolvimento tecnológico incomensurável (que conduz à contínua substituição do trabalho humano pela máquina) se assiste ao aumento da precarização/exclusão ${ }^{3}$ de um grupo cada vez maior de indivíduos sem emprego e sem esperanças de o conseguirem (na União Europeia aproximava-se em finais dos anos 90 dos vinte milhões de indivíduos), o que se traduz no aumento da insegurança, ficando os mesmos, sujeitos a programas residuais de assistência, ou em casos mais extremos desprovidos de toda a proteção social.

Em complemento deste quadro, e de acordo com Paulo Netto, estamos perante o «[...] fracasso do único ordenamento sociopolítico que, na ordem do capital, visou expressamente compatibilizar a dinâmica da acumulação/valorização capitalistas com a garantia de direitos políticos e

\footnotetext{
3 Para Robert Castel «ser excluído é "caminhar" fora da ordem do trabalho fora das redes concretas de solidariedade» (1994: 15), devendo aqui, ser acrescentado que «a exclusão não é somente um estado a analisar em si mesmo. É também um resultado que se relaciona com o que se passa antes: ao nível da organização do trabalho, da competitividade das empresas, das reconversões industriais. Isto é, por relação ao centro da vida económica e social, o que produz a riqueza e o poder» (1994: 21).
} 
sociais mínimos» (1994: 65), isto é, a crise do Estado Providência ${ }^{4}$. Paralelamente dá-se o reforço da corrente Neoliberal - defensora, segundo alguns dos seus críticos, a «refilantropização da sociedade».

Dito de outro modo, a uma Crise Económica do Estado que se manifestou desde inícios dos anos 70 e que, de acordo com Marc-Henry Soulet (1996), se plasmou, por um lado, numa crise de financiamento (cortes nos orçamentos sociais, redução dos défices, fragilização de certas prestações sociais) e, por outro, numa crise de eficácia (aumento dos investimentos em paralelo com a manutenção ou ressurgimento das desigualdades ou da marginalidade); veio-se juntar uma Crise Ideológica, onde se questiona, segundo Soulet, a «crise do progresso social» (equacionando-se a conceção tradicional dos direitos sociais) e os «limites da solidariedade pública», ou seja, onde se levantam «interrogações relativas à detenção pelo Estado do monopólio da solidariedade» ${ }^{5}$.

Assim sendo, gostaríamos de explicitar melhor alguns traços da corrente neoliberal. De acordo com Silva e Silva «o projeto neoliberal busca suas bases de sustentação no velho liberalismo, reconhecendo e, em parte, até estimulando a auto-organização da sociedade, desde que se oriente para interesses puramente corporativos e "privados" [...]. Apregoa a apologia à privatização, deslocando a esfera pública para o mercado, e a solução de conflitos e o atendimento às procuras sociais ficam por conta de um 'estado mínimo`» (1992:107).

O seu principal objetivo é a retração da intervenção estatal, tanto ao nível da afetação de recursos para programas sociais, como no que diz respeito à regulação económica que vinha sendo desenvolvida visando a estagnação do desemprego, visto que, consideram que os gastos sociais são a principal causa do declínio económico.

Destarte, assiste-se a uma desregulamentação das responsabilidades do Estado (redução das políticas públicas e despesas ao nível social) e,

${ }^{4}$ O Estado Providência keynesiano (implementado gradualmente nas economias ocidentais mais desenvolvidas a partir da segunda grande guerra) tinha como princípios básicos: uma política de pleno emprego; o desenvolvimento de serviços universais ou tendencialmente universalizáveis, visando a satisfação de necessidades básicas da população; o desejo - por intermédio de instrumentos vários - de manutenção de um nível nacional mínimo de condições de vida; não descurando valores como a igualdade e o bem-estar, pretendia garantir ao indivíduo as condições necessárias à sua integração na sociedade, assegurando-lhes padrões mínimos de qualidade de vida; sobre estas questões, vide Ramesh Mishra (1990).

Na ótica de Pierre Rosanvallon (1995), uma das dimensões que atualmente se vivencia é de carácter filosófico, onde são postos em causa - desagregação - os princípios organizadores da solidariedade em paralelo com o insucesso da conceção tradicional dos direitos sociais. 
consequentemente, à não efetivação dos direitos sociais, verificando-se o aumento dos grupos excluídos, porque, ao se assistir à diminuição da afetação de recursos, o impacto das políticas neoliberais irá atingir primordialmente os mais baixos estratos sociais impossibilitando a inclusão social ou a mobilidade ascendente, visto que, ao se privatizarem serviços constata-se que enquanto alguns grupos populacionais podem continuar a adquirir os serviços no mercado - porque possuem meios económicos para tal - outros há que não têm essa possibilidade, tendo que se contentar com serviços públicos residuais. Explicitando, temos vindo a assistir a uma diminuição dos gastos ao nível social em paralelo com o aumento dos problemas sociais ${ }^{6}$.

Paralelamente, como já referimos, os neoliberais continuam a defender a refilantropização da sociedade, refilantropização essa, que pode ser facilmente entendida por intermédio do discurso do neoliberal Vaclav Klaus: «o sistema social da Europa Ocidental está demasiadamente amarrado por regras e pelo controle social excessivo. $\mathrm{O}$ Estado de bem-estar, com todas as suas transferências de pagamentos generosos desligados de critérios, de esforços ou de méritos, destrói a moralidade básica do trabalho e o sentido de responsabilidade individual» (In Anderson, 1995: 18).

Constatamos então que, a situação de crise em que se encontra o Estado Providência leva a que os apologistas das correntes neoliberais critiquem de forma inexorável a intervenção da esfera estatal, defendendo a substituição da mesma por agentes privados e/ou redes familiares (revalorização da esfera da sociedade civil/familiar vs. crítica à intervenção da esfera estatal). Pessoalmente pensamos que, antes de adotar atitudes tão radicais deve-se refletir sobre as possibilidades que existem no que concerne à partilha de responsabilidades entre o público e o privado, definindo claramente os moldes em que a restruturação se deve plasmar de forma a ultrapassar a crise, visto que, embora sejamos de opinião de que é possível efetuar-se um trabalho complementar entre ambas as esferas, jamais poderemos aceitar que a esfera das solidariedades familiares se substitua ao «dever» da esfera Estatal, porque, aquela, ao ter por base relações recíprocas ${ }^{7}$, nunca se poderá

\footnotetext{
${ }^{6}$ Gostaríamos ainda de referir que, apesar de utilizarmos o termo Neoliberais, estamos conscientes das diferenças que existem entre as várias correntes, i.e., as críticas que têm sido feitas ao Estado Providência diferenciam-se pela sua radicalidade, indo desde a Direita Radical (Nova Direita, Neoliberais) até a outras correntes principais da direita - menos radicais - (Neoconservadores, tais como, os Liberais Céticos do Centro e os Sociais Libertários); sobre estas questões, cf. Maurice Roche (1992: 714).

${ }^{7}$ Entendendo-se a reciprocidade, segundo Polany, como sendo «[...] uma forma de integração socioeconómica, baseada na troca de relações entre grupos simétricos
} 
constituir como «geradora» de direitos. Por outras palavras, o referido remete para a existência de uma descontinuidade do sentido da solidariedade quando caminhamos da família para o Estado, porque, enquanto na primeira, esse mesmo sentido, emerge a partir da relação interpessoal, na segunda torna-se um enjeu social e político (Soulet 1997: 13).

Gostaríamos igualmente de chamar a atenção para um outro texto deste autor, na medida em que o mesmo ao analisar as possíveis relações que se estabelecem ao nível da solidariedade entre o Estado e a sociedade civil, defende que se deve «romper com a ilusão simplista, mas muito presente, de que estamos perante uma solução milagrosa face à crise de financiamento e de eficácia, i.e., que a intervenção pública ao transferir pura e simplesmente os encargos em matéria de solidariedade da coletividade pública para as solidariedades informais, consiga resolver esse problema» (Soulet, 1996: 15).

\subsection{Mediações que perpassam a prática do Serviço Social}

Não descurando o anteriormente referido, torna-se pertinente encetar uma breve exegese sobre a possível interligação que existe entre a crise que atualmente vivenciamos e a prática do serviço social, ou seja, chamando à atenção para algumas modificações que a prática do serviço social já está a sofrer em outros contextos, modificações essas que, também poderão, possivelmente, emergir em Portugal.

Seguindo de perto Michael Fabricant et al (1992) verificamos que, a política de contenção de custos - nos EUA -, tem vindo a propugnar o aparecimento de novas questões - ao nível da estrutura dos serviços e natureza do trabalho - que influenciam o desempenho da prática profissional, nomeadamente:

i) Verifica-se um aumento da dificuldade, por parte do Estado e das Instituições, em recrutar pessoal técnico qualificado, recorrendo-se cada vez mais a indivíduos com menores qualificações e/ou em casos extremos ao voluntariado, dando-se consequentemente uma desprofissionalização da intervenção em conjugação com alterações ao nível salarial e uma maior flexibilização no emprego;

ii) Paralelamente, dada a existência de um hiato entre os recursos e as necessidades, aos assistentes sociais é pedido, por um lado, para dar resposta a um maior número de casos que se caracterizam por uma maior heterogeneidade e, por outro, num menor espaço de tempo - dando-se prioridade ao quantitativo comparativamente ao qualitativo. Isto conduz,

[relações sociais primárias: parentesco, amigos, família], onde a retribuição de dádivas prevalece» (apud Yuri Kazepov, 1996: 4). 
por um lado, a uma maior racionalização do acesso aos serviços ${ }^{8}$ e, por outro, a uma menor disponibilidade de tempo, por parte do assistente social, para analisar em conjunto com o utente as problemáticas múltiplas que o mesmo vivencia, substituindo-se assim, em muitos casos, a habilidade/competência técnica por tarefas rotinizadas. Por outras palavras e, de acordo com Henry Soulet (1996), assistimos ao aparecimento da urgência das respostas financeiras o que dificulta o acompanhamento a longo prazo e, em consequência, à diminuição da visibilidade que os preceitos educativos sempre tiveram na prática dos assistentes sociais;

iii) As exigências de «produtividade» conduzem a uma redução da autonomia na análise/intervenção dos assistentes sociais em relação às problemáticas sociais, bem como à não participação na conceção dos orçamentos e/ou na definição das prioridades dos serviços.

Deste modo, é primordial que os assistentes sociais percebem o contexto geral em que a sua prática se insere, percebendo como é que, por um lado, funciona o Estado e como é que o mesmo se relaciona com o mercado e a sociedade civil e, por outro, que alterações têm vindo a surgir ao nível do mercado de trabalho, porque, pensamos, só por intermédio desta perceção é que se poderá compreender a prática que realizamos, quer dizer, estando cônscios do papel que desempenham dentro de toda esta complexidade.

Nas palavras clarividentes de Marilda Iamamoto, deve-se repensar a formação dos assistentes sociais, para que a mesma possibilite aos futuros profissionais «[...] compreender criticamente as tendências do atual estágio da expansão capitalista e as suas repercussões na alteração das funções tradicionalmente atribuídas à profissão e no tipo de capacidade requerida pela "modernização" da produção e pelas novas formas de produção da força de trabalho; [no fundo, pretende-se que essa formação] dê conta dos processos que estão produzindo alterações nas condições de vida e de trabalho da população que é alvo dos serviços profissionais, assim como das novas procuras dos empregadores na esfera empresarial» (1995: 12).

Apresentada que está, de uma forma sintética, a experiência que vivenciamos, ao refletirmos sobre a noção de cidadania, nunca nos poderemos esquecer que a importância desta análise se coloca ao nível das possibilidades que essa mesma noção pode possuir para facilitar não só a compreensão da nossa experiência concreta, como também,

\footnotetext{
${ }^{8}$ Segundo Lipsky «racionalizar não só reduz o número de pessoas que procuram os serviços, mas também transforma os programas de direitos em programas condicionalmente restritos (....).» (apud Michael Fabricant et all, 1992: 77).
} 
possivelmente, contribuir para o minorar das problemáticas existentes na mesma.

\section{DUAS TRADIÇÕES CONCEPTUAIS DA CIDADANIA: LIBERAL-INDIVIDUALISTA E REPUBLICANA-CÍVICA}

Sabendo, então, que nos encontramos em presença de duas tradições, que encaram distintamente a cidadania e por consequência, o papel do cidadão, vamos seguidamente explicitar as mesmas. De acordo com Michael Walzer (1975), Jürgen Habermas (1994), Klaus von Beyme (1996), vamos encontrar:

i) Uma conceção individualista e instrumental enraizada na teoria liberal - Tradição Liberal-Individualista -, que concebe a cidadania, como algo em que a pertença a uma instituição, que pode ser uma comunidade ou um Estado-nação - que assegura um status legal -, se caracteriza pela receção passiva (a participação dos cidadãos não é realçada), onde são valorizados os direitos individuais e a igualdade de tratamento. Logo, nesta conceção, o cidadão - enquanto Staatsburger?', i.e., sujeito do Estado - serve como meio para a reprodução do Estado em troca de alguns benefícios (liberdade, proteção, etc.). Quer dizer, esta tradição apreende as instituições, que permitem a participação na cidadania, de um modo individualista e instrumental - versão mais estática;

No concernente ao anteriormente referido, gostaríamos de assinalar que, ao se falar em sujeito do Estado, verifica-se que uma das questões que atualmente se coloca relativamente a esta abordagem da cidadania, é a das dificuldades que cada vez mais se levantam à interligação do conceito de cidadania com o de nacionalidade ou identidade nacional, ou seja, ao se falar em cidadania transnacional, nomeadamente, na União Europeia, há necessidade de repensar a abordagem que enuncia como aspeto básico da cidadania o status/pertença a um determinado Estado ${ }^{10}$.

i) Tomando agora em atenção a segunda conceção - versão mais dinâmica -, verifica-se que o debate sobre a cidadania, nesta perspetiva, já não se limita somente à relação entre o indivíduo e o Estado, mas é alargado ao contexto mais vasto da sociedade civil, tomando-se em linha de conta as inter-relações que se estabelecem entre os diferentes membros de uma comunidade e a forma como as mesmas podem propugnar alterações, aos mais variados níveis, na evolução dessa mesma

\footnotetext{
Kant fazia uma distinção entre Staatsburger (cidadãos ativos) e Staatsgenossen (cidadãos passivos), (Gomes Canotilho, 1995). Nós ao nos referirmos ao termo, temos em mente um cidadão passivo.

Sobre este aspeto pode-se, entre muitos outros autores, cf. Antje Wiener (1996).
} 
comunidade, nomeadamente, o reconhecimento pela comunidade da extensão dos direitos a todos.

Assim sendo, pode-se dizer que a mesma tem subjacente, um entendimento comunitário e ético, na tradição da filosofia política de Aristóteles. Deste modo encontramo-nos em presença da Tradição Aristotélica ou Republicana-Cívica - envolvendo a cidadania atividade política ou o «moeurs politiques» ${ }^{11}$.

Por outras palavras, a cidadania é concebida em analogia com um modelo onde predomina a «conquista» da pertença a uma comunidade ético-cultural autodeterminada, i.e., constatamos que os laços que interligam o indivíduo com a comunidade são muito mais fortes. Perante isto, pode-se então dizer que esta segunda perspetiva reserva um papel mais ativo para o cidadão, dado que, a realização da cidadania, de acordo com Habermas (1994: 26), está dependente da existência de uma prática conjunta de autodeterminações.

Em consequência, a participação no poder, de acordo com Charles Taylor, é entendida «[...] como a essência da liberdade [...], sendo capaz de durante a maior parte do tempo participar na formação do poder consensual, onde cada um pode ser identificado perante os outros. Mandar e ser mandado, significa, que pelo menos durante algum tempo os 'governantes' podemos ser 'nós' e não sempre os 'outros'» (apud Habermas, 1994: 26), ou, nas palavras clarividentes de Colin Crouch, a essência da cidadania apreende-se quando existe «participação direta nos negócios públicos da comunidade» (1996: 2), devendo o indivíduo sentirse envolvido/identificado com o destino individual e coletivo, agindo sobre os desafios reais dos homens e das mulheres à escala onde os problemas se colocam, tentando ultrapassar o sentimento de impotência que tanta vezes nos assola, enfim, entendendo a cidadania, na aceção de Calame (1995), como sendo a crença na nobreza e na possibilidade do político.

Não descurando o enunciado relativamente à participação no poder, gostaríamos de sinalizar o contributo de Walzer (1975), porquanto, o mesmo pode clarificar um pouco melhor as diferenças existentes entre as duas perspetivas. Deste modo, para este autor, uma das diferenças mais significativas entre as duas perspetivas, encontra-se ao nível das possibilidades de ampliação das mesmas, ou seja, enquanto no primeiro caso - dado o grau de ampliação não influenciar a qualidade de proteção - pode-se dar uma ampliação sem limites, na segunda conceção, verificamos que, essa ampliação sofre restrições, pois, a qualidade/oportunidade da participação diminui «proporcionalmente» ao

${ }^{11}$ Para uma análise mais aprofundada da tradição aristotélica de cidadania, vide Hannah Arendt (1958); Judith Shklar (1991: 42-4). 
aumento do número de cidadãos. Por outras palavras, uma das características da cidadania, de acordo com Crouch (1996) é ceteris paribus, ou seja, existe uma relação antitética entre a intensidade dos direitos e a extensão dos mesmos em termos de números, o que se verifica por exemplo, comparando a cidadania de Atenas - restritiva em termos de cobertura, comparativamente à cidadania de Roma, mas muito mais intensa do que esta.

Será igualmente importante referir que, segundo Michael Walzer, ambas as perspetivas são parcialmente verdadeiras, sendo por isso difícil atenuar as diferenças existentes entre elas. No entanto, recorrendo ao conceito pluralista de cidadania, recupera a importância da participação do cidadão - em grupos menores (com uma ação não trivial), que define como «uma série de círculos [esferas] parcialmente coincidentes, dentro de um círculo [esfera] maior que é o Estado (...) [que desafiando a autoridade desse mesmo Estado, permitem que os cidadãos cumpram os seus deveres públicos]» (Walzer, 1975: 188-89).

Apresentadas que estão, de um modo necessariamente sinóptico ${ }^{12}$, as duas perspetivas, gostaríamos de referir que, pessoalmente, nos colocamos mais na linha da segunda perspetiva, não considerando no entanto, que elas se excluam mutuamente, devendo sim, ser entendidas como complementares.

A adoção deste posicionamento justifica-se pelo facto de, em nossa opinião, a perspetiva mais estática se aproximar muito de uma abordagem mais ou menos linear - em patamares - da consolidação da cidadania, que se inicia nos direitos civis e «termina» nos direitos sociais. Por outras palavras, partindo de uma classificação legal dos direitos, tem principalmente em atenção, por um lado, a expansão desses mesmos direitos ${ }^{13} \mathrm{e}$, por outro, a inclusão de um número cada vez maior de indivíduos. Consequentemente, uma análise subtil, facilmente evidencia alguns dos condicionalismos presentes na perspetiva marsheliana, nomeadamente: (i) o predomínio da masculinidade, i.e., refere-se primordialmente aos direitos masculinos; (ii) não apreende as modificações propugnadas na estrutura familiar com a entrada da mulher no mundo do trabalho; (iii) a evolução linear dos direitos não captura as lutas das minorias étnicas; (iv) a evolução linear coloca problemas quando são tomadas em consideração experiências concretas países de leste, Portugal durante o estado Novo; (v) a leitura que é feita sobre essa evolução é contrariada pelo caso concreto da União Europeia ${ }^{14}$.

\footnotetext{
${ }^{12}$ Para uma análise mais aprofundada destas questões, cf. Manuel Menezes (2001).

${ }^{13}$ Num espaço muito concreto e delimitado, visto o território em análise ser a GrãBretanha.

${ }^{14}$ Sobre estas questões pode-se cf., entre muitos outros autores, Tom Bottomore (1992); Maurice Roche (1992); Manuel Menezes (1999; 2001).
} 
Perante isto, facilmente constatamos que este tipo de análise não dá conta da complexidade da cidadania na atualidade. Paralelamente, podese igualmente afirmar que a análise peca pela ausência de conteúdo, i.e., segundo a aceção de Jürgen Habermas, este tipo de análise não nos diz nada acerca do atual uso da cidadania ativa, ou nas palavras prescientes de Michael Walzer «(...) nada nos diz acerca das dimensões políticas e morais da cidadania» (1975: 179), ou seja, de que forma e por que meios é que o indivíduo pode influenciar as mudanças democráticas do seu e/ou dos outros - status (Jürgen Habermas, 1994: 31). Em suma, como é que o indivíduo pode agir politicamente.

Assim sendo e, antes de explicitarmos o que entendemos por ação política, gostaríamos de referir que esta deve ser um ato de livre e espontânea vontade, não podendo ninguém ser compelido por normas de qualquer espécie a ser um cidadão ativo. No que diz respeito a este aspeto, de uma forma geral todos os autores consultados partilham desta opinião. De acordo com Judith Shklar, uma das vantagens que a democracia representativa possui, é a de permitir que o cidadão tenha a possibilidade de participar na política ou de a ignorar completamente (1995, 88). Semelhante opinião encontramo-la em Michael Walzer (1975), ao afirmar que os limites para a «obrigação política» são de caráter subjetivo, afirmando igualmente que, quando o indivíduo não tem consciência do que pode fazer na política, ou não possui qualquer compromisso com os negócios públicos, não se pode obrigar - por força ou por fraude - esse mesmo cidadãos a agir politicamente, porque, com esta atitude não se serve o ideal da cidadania (1975: 155, 189). Por último, mas não menos importante, é o contributo de Jürgen Habermas, ao salientar o facto de que, o uso da lei, mesmo que seja para tornar um cidadão ativo, contém em si mesmo algo de totalitário (1994: 26)

Não descurando, então, o anteriormente enunciado e tomando em atenção a noção de cidadania ativa, gostaríamos de sublinhar que, durante muito tempo, as únicas formas de agir consideradas políticas eram a «acção (praxis)» e o «discurso (léxis)», no entanto, hoje em dia, de acordo com Arendt (1958: 34, 51), verifica-se que cada vez mais o comportamento substitui a ação como principal forma de relação humana., quer dizer, encontramo-nos perante a despolitização da experiência, onde a ação política se restringe ao voto de quatro em quatro anos ${ }^{15}$.

15

Ainda no que diz respeito à despolitização da experiência, ganha importância o contributo de Klaus Eder (1996). Este autor faz referência aos problemas que se colocam no modo como os cidadãos contextualizam os dois princípios centrais inerentes à ideia de democracia, as eleições e o espaço público, no que diz respeito ao primeiro, considerado pelo autor uma forma institucional de participação, encontra-se 
Perante este cenário, é necessário refletirmos sobre necessidade da repolitização do agir humano, ou no caso concreto dos assistentes sociais a trabalhar não só, mas também em autarquias, reinventar a democracia de base: da comunidade, do bairro, da vizinhança (Jean-Marrie Delarue, 1991). Este processo de repolitização poderá passar, de acordo com Florence Robert (1991), por exemplo, pela pedagogia do acesso à palavra, i.e., permitindo que populações excluídas passem do silêncio à expressão de reivindicações, que se passe da palavra negativa à palavra positiva.

Seguindo este raciocínio gostaríamos, então, de apresentar algumas considerações sobre o que pode ser entendido ao nível da prática como ação política (tomando em atenção a experiência), ou seja, em cada momento concreto, é necessário que tomemos consciência de qual é a ação política mais urgente, dada a impossibilidade de dar resposta simultaneamente a todos os problemas. Isto significa, de acordo com Michael Walzer (1983), que o cidadão tem que estar preparado para no momento exato, ser capaz de atuar - decidindo, escutando e ser escutado - em conjunto com outros cidadãos, responsabilizando-se por suas palavras e atos.

Deste modo, poderemos afirmar que um dos deveres mais importantes do cidadão é a preocupação com a sua formação política. Entendendo-se aqui, o político, de acordo com Hannah Arendt, como sendo o agir de muitos e não de poucos, ou seja, a política é o ato/tarefa de todos, não se podendo no entanto argumentar que, quando um cidadão age isoladamente, não há ação política, visto que, «quando a dignidade desaparece e um só homem tem dignidade, ele tem a dignidade de toda a humanidade».

Em consequência, se partirmos do pressuposto de que todo o cidadão dispõe de potencial para agir politicamente, será necessário percorrer a «estrada» que transforma a potência em efetividade, de forma a «perpetuar» a vivacidade e a integridade do agir político, tentando clarificar as condições e possibilidades de ação.

na prática desvirtuado, dado que a sua transformação numa rotina levou a que os cidadãos votem não por convicção na sua essência democrática, mas mais, tendo subjacente um sentimento de obrigatoriedade, dado que, em nossa opinião, de acordo com o «sistema político/eleitoral» em que vivemos atualmente, alguns - poucos - são eleitos para governar/agir politicamente e, os outros - os muitos - são governados, assumindo um papel passivo durante a maior parte do tempo, só se tornando «ativos» - pelo voto - de quatro em quatro anos; relativamente ao espaço público (fórum da livre troca de ideias racionais na ótica habermasiana), argumenta o autor, transformou-se num espetáculo dominado pelos media, onde a «argumentação racional» deu lugar à «dramatização simbólica» (1996: 2-4). No que concerne, por exemplo, à influência da publicidade nas eleições primárias nos EUA, cf. Michael Walzer (1983: 316-7); Pierre Héritier (1995: 26). 
Relativamente às possibilidades de ação, gostaríamos de chamar a atenção para a importância da análise das questões de poder, dado que, as mesmas permitem a apreensão das possibilidades de agir na relação com o outro e, só aproveitando essas possibilidades - pela ação - é que poderemos caminhar da potencialidade para a efetividade, i.e., seguindo Bragança de Miranda (1994), temos que ter sempre em atenção as «(...) condições de possibilidade anunciadas na própria ideia de política».

Verificamos deste modo que, muitas vezes, a decisão sobre o que fazer (os problemas só podem ser resolvidos praticamente, no concreto) é uma questão extremamente grave, mas é uma questão política, porque, se não soubermos responder politicamente, corremos o risco de que a violência campeie. Logo, temos de definir em cada momento, o que é mais urgente politicamente e responder politicamente ou deixar que alguém responda por nós, porque, em todo o estado de acção a urgência prevalece sobre a definição (Bragança de Miranda, 1994).

Para uma melhor compreensão do entendimento que fazemos de uma situação de urgência, poderemos recorrer ao contributo de Henry Soulet (s/d: 2-3, 8). Segundo este autor, uma situação deste tipo implica um ação rápida, porque, quando nos encontramos em presença de algo que é insuportável e/ou de algum procedimento intolerável, devemos aproveitar todas as oportunidades que existem com o intuito de tentar evitar ao máximo as vantagens que a situação de urgência pode ganhar perante a (in)ação. Logo, se o estado de urgência não impossibilita a ação, só aproveitando todas as possibilidades é que poderemos evitar a concretização da ameaça, controlando a situação, minorando o problema, evitando, em última instância, a catástrofe.

Infelizmente o que temos vindo a verificar é que a passividade tem prevalecido, dado que, nós não temos vindo a agir politicamente sobre o sistema, quer dizer, em vez de uma ação livre tendo em vista a sociedade justa, o que se tem verificado muitas vezes é uma passividade em troca de segurança individual.

Paralelamente a tudo isto, teremos igualmente que estar conscientes que a qualidade da ação que, a ação política exige, não é algo dado de forma gratuita, não bastando somente ser um «bom cidadão» sendo necessário tentar, de acordo com Judith Shklar (1991), a aproximação ao «cidadão ideal», aproximação essa, que exige, muitas vezes, todo o trabalho de uma vida. Dito de outro modo, a qualidade da ação política é uma qualidade que deve ser socialmente reconhecida, aquilo que Arendt denomina de «qualidade da excelência», devendo o indivíduo ser capaz de estar à altura das situações, merecendo o «auto respeito» e a «honra pública». Para isso, é necessário conhecer-se a si mesmo enquanto cidadão que tem possibilidades de tomar opções, aceitando o risco para si e para os seus concidadãos, visando alcançar uma comunidade boa 
Michael Walzer (1983: 320-21). No entanto, nada nos garante que saibamos aproveitar as oportunidades, mas certamente que uma cidadania ativa, que «supere o orgulho e o impulso em associação a outras pessoas honradas» é certamente uma ação política que produzirá, segundo Michael Walzer, cidadãos «livres, porque se governam a si mesmos; virtuosos, em virtude do seu espirito público e poderosos, porque suas ações produzem efeitos significativos».

Embora cônscios da dificuldade que existe em encontrar este «tipo» de cidadão, esta reflexão é importante na medida em que «[...] nos serve antes de mais, de instrumento crítico permanente, permitindo evidenciar a imperfeição da nossa democracia e a falta de zelo que a maior parte de nós manifesta em relação aos negócios públicos» (Judith Shklar, 1991: 20-1).

\section{DESAFIOS PARA O SERVIÇO SOCIAL PROMOTOR DA CIDADANIA ATIVA}

Tomando em atenção a argumentação que tem vindo a ser adotada, nomeadamente no respeitante à conceção de cidadania em analogia com um modelo onde predomina a «conquista» da pertença a uma comunidade ético-cultural autodeterminada gostaríamos de tecer algumas considerações.

Se entendermos esta comunidade, como sendo constituída por um conjunto de inter-relações entre vários atores sociais e, se ao defendermos que a cidadania ativa implica a partilha - no mínimo - de características culturais entre os vários membros da sociedade, verificamos que a maioria dos utentes do serviço social se encontram excluídos da cidadania formal - tanto por opção no caso dos direitos políticos (cf.. sobre este aspecto Yannis Papadopoulos, 1996: 10), como por obrigação relativamente aos restantes - e, sabendo que esta exclusão, devido ao conjunto de características que lhe estão inerentes, propugna a exclusão dos «padrões de normalidade social», facilmente concluímos que, esses indivíduos, dificilmente se poderão tornar cidadãos ativos enquanto não partilharem essas características mínimas exigíveis para a cidadania ativa.

Logo, é importante que o debate relativamente a estas questões seja aprofundado, visto que, ao falarmos de cidadania teremos que nos questionar sobre o que é a verdadeira cidadania, porque, embora todos os indivíduos sejam considerados formalmente cidadãos - exceção feita aos estrangeiros, onde somente se pode falar em cidadania restrita -, somente a alguns, é permitido partilhar da cidadania efetiva. Isto é, até que ponto poderemos falar em cidadania para indivíduos que não têm um teto sobre o qual possam viver condignamente ou, o que significa o exercício da cidadania política para aqueles que estão sem emprego e por 
consequência sem reconhecimento social, em suma, como se pode ser um cidadão ativo quando se tem um emprego precário, sabendo que no atual mercado de trabalho a qualquer momento se pode cair numa situação de exclusão ${ }^{16}$.

Assim sendo, sabendo, por um lado, que a diferença entre o estatuto formal - de cidadão e a cidadania envolvendo ação pode ser muito significativa (diferença entre cidadão virtual e cidadão real, na aceção de John Friedmann, 1992) e, por outro, que a maioria dos utentes do serviço social são excluídos em ambas as situações, pensamos, ser importante refletir sobre o modo como o assistente social pode desempenhar um papel de extrema importância no aumento de oportunidades/extensão para esses utentes excluídos - de participação ativa na comunidade. Isto é, como é que os assistentes sociais podem conceber formas concretas que permitam um envolvimento/participação mais sustentada dos utentes

16

Sobre este último aspeto, pensamos ser de extrema importância, a análise encetada por Judith Shklar (1991: $2^{\circ}$ cap.) no que concerne à esfera do trabalho. Considerando esta, uma das esferas essenciais da cidadania, a autora desenvolve uma análise arguta, tentando demonstrar as interconexões que existem entre as várias esferas em que o indivíduo se move. Na aceção da autora o acesso à esfera do trabalho está associado a todo um conjunto de atributos, que permitem ao indivíduo tornar-se cidadão, nomeadamente, a independência económica que permite a liberdade para..., autonomia essa, que por sua vez se interliga com o respeito, consideração, reconhecimento da sociedade para com o indivíduo e, em consequência com o estatuto social. Paralelamente, o não acesso a esta esfera está em conexão com a (in)autonomia e, consequentemente com a perca do respeito por parte dos concidadãos, diminuição do prestígio social, da dignidade, da honra, da autoestima e do estatuto social. Se esta argumentação é aceitável, uma questão se nos coloca, será que os milhões desempregados atualmente existentes no mundo, o são por opção própria - falha individual - como cada vez mais apregoam os neoliberais? Pensamos que não, porque, sabemos perfeitamente que, a partir do momento em que se individualiza uma problemática se está a despolitizar a ação, ou seja, na aceção de Marc-Henry Soulet «[...] a exposição de casos individuais contribui para encobrir a realidade social [...], visto que, a descontextualiza, porque, a reduz à apreensão imediata do espectador que não consegue reagir» (s/d.: 10). Mais ainda, de acordo com Philip Mondolfo «o aumento do desemprego e a sua extensão atual [...] invalida a imagem do "indolente" que não quer trabalhar ou do "marginal" que escolheu a liberdade. O indivíduo "faltoso" deu lugar, no imaginário coletivo, à vítima da crise, ao qual a sociedade propõe um direito que sistematicamente escapa às regras das instituições, e ao poder discricionário das administrações e dos técnicos da assistência, sob a reserva de um trabalho de inserção» (1997: 57). Mas, ainda mais importante do que esta evidência é, a reflexão que pensamos ser necessária desenvolver no que diz respeito aos atributos negativos que estão associados ao desemprego, i.e., até que ponto é aceitável atualmente, associar à esfera do trabalho a dignidade, o respeito, a honra, o estatuto social..., quando existem milhões de pessoas sem possibilidade de acesso a essa mesma esfera e em consequência privados desses mesmos atributos; sobre a importância da esfera do dinheiro, pode-se cf. Michael Walzer (1983: cap IV). 
na comunidade, tentando desta forma apreender a partir das ações desenvolvidas pelos profissionais, o potencial político das mesmas.

Não devemos no entanto esquecer quão difícil é a tarefa de mobilização dos utentes que, pode facilmente ser explicitada pela afirmação de Michel Rocard «nada é mais difícil do que, fazer emergir a procura, a expressão das necessidades, ou das expectativas daqueles que económica ou socialmente vivem à margem das nossas sociedades» (apud Jean-Marie Delarue, 1991: 16) e, em paralelo com esta situação, pensamos, ainda haverá que desenvolver estratégias de sensibilização em relação aos $\operatorname{autarcas}^{17}$, porque, em nossa opinião, não só é difícil mobilizar a população, como também, os próprios eleitos locais - e quiçá alguns assistentes sociais e os cidadãos de uma forma geral - que, em muitos casos, ainda não demonstram muita vontade para que essa participação se efetive. Daí se poder afirmar que, em muitas situações hoje em dia, a exclusão da participação não se deve somente a fatores económicos, mas também à falta de um sentido de interesse público ${ }^{18}$, de um sentido da ação pública - por parte de uma grande percentagem dos cidadãos - para que a situação se modifique.

Destarte, será necessário refletir sobre os défices de democracia participativa, tentando encontrar estratégias que propugnem o aparecimento de uma cultura política que conduza ao envolvimento/empenhamento coletivo e à participação local, ou seja, a questão que o assistente social deve colocar a si próprio é: como é que eu posso desenvolver uma ação de modo a que consiga tornar mais real na sociedade a cidadania das pessoas? Na tentativa de resposta a esta questão, apontamos seguidamente algumas estratégias que, possivelmente, poderão facilitar esse percurso.

\footnotetext{
${ }^{17}$ Georges Gontcharoff, defendendo a existência de um défice de expressão por parte das populações pouco integradas, faz, igualmente, referência aos autarcas, afirmando que existe um «deficit considerável, na aceitação por parte dos eleitos dos conflitos que são necessários. Muitos eleitos procuram principalmente, por intermédio de uma falsa participação, um consenso sobre uma participação anestesiante, descurando que o conflito é produtor de progresso ao nível local» (1991: 56).

18

Pensamos poder referir aqui, a necessidade de revalorizar os deveres do cidadão para com a comunidade, dado que, usualmente o debate em torno da cidadania tem decorrido primordialmente à volta dos direitos ficando os deveres um pouco submersos.
} 
Figura n. ${ }^{0} 1$ - Estratégias para a Promoção da Cidadania

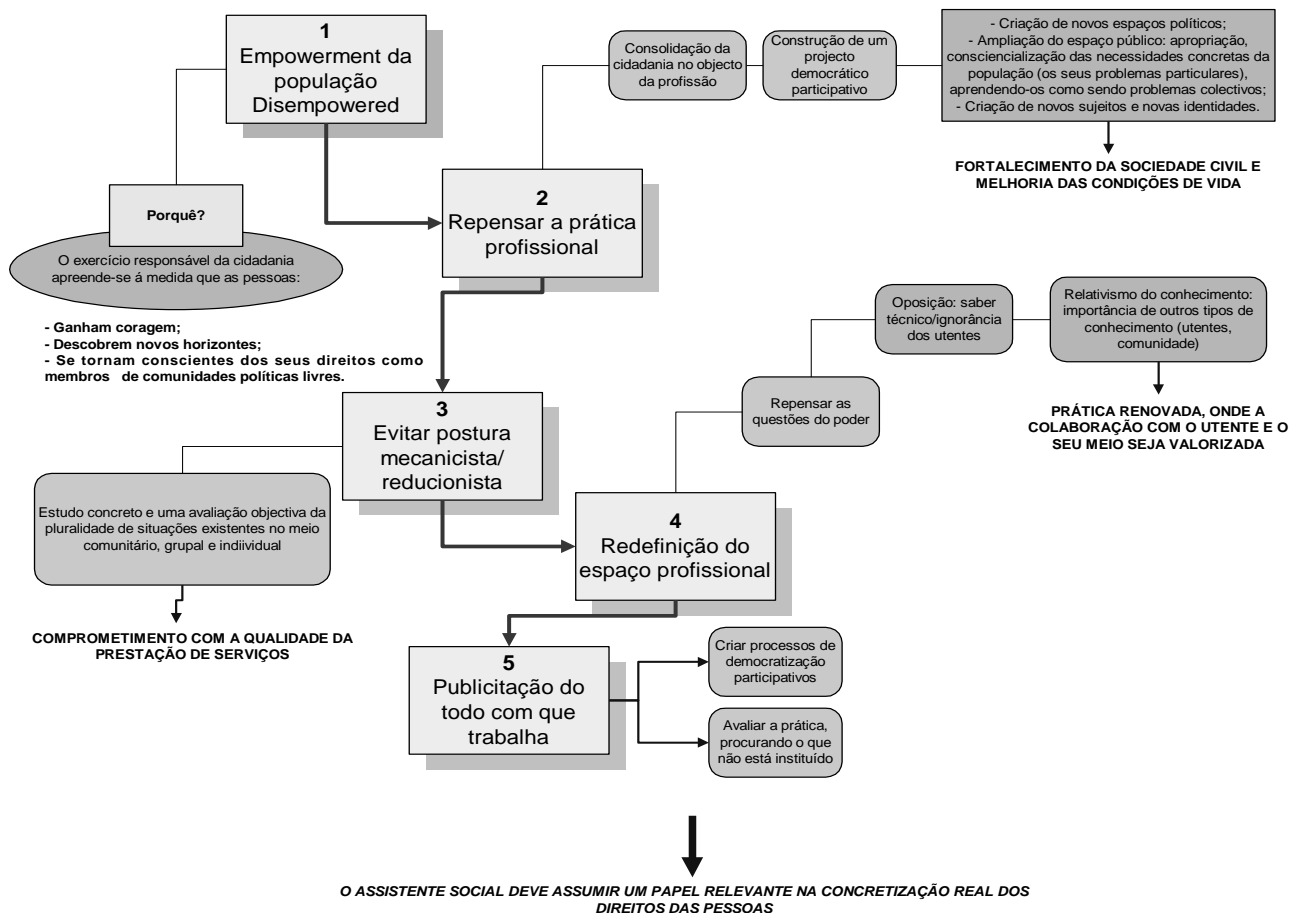


Tomando por base o esquema supra, defendemos que, a formação de vínculos entre a população e o assistente social no sentido de encontrarem a melhor resposta para a superação de um problema, é o ponto basilar de uma ação que se pretenda promotora da cidadania. E, apesar de reconhecermos as dificuldades inerentes à construção de um processo decisório partilhado, somos de opinião de que partindo da base (para chegar ao topo) por intermédio da passagem do «real ao próximo», talvez consigamos (ainda que devagar) ir construindo uma cidadania que atenue a exclusão social.

$\mathrm{Na}$ realidade, o assistente social terá que saber analisar o «Local», de forma a conhecer as forças com que pode contar, recusando assim, «cruzar os braços», procurando desencadear ações inovadoras, quando as condições existentes o permitirem.

Sintetizando, os profissionais devem assumir uma posição críticoconstrutiva por «oposição» ao que está instituído: facilitando/mobilizando a participação dos utentes e da comunidade; (ii) propugnando o aparecimento de espaços de expressão e participação em processos decisionais; (iii) «consciencializando» os utentes das capacidades pessoais, bem como, da forma como as mesmas podem ser interligadas com uma ação que vise a efetivação dos seus direitos; (iv) participando em ações comunitárias que conduzam à assumpção dos problemas como dizendo respeito a todos, enfim, mobilizando os recursos - humanos e materiais - institucionais e comunitários visando o crescimento da comunidade como um todo, pois só assim, pensamos, poderá ser desencadeada uma ação política que valorize as potencialidades do agir humano, transformando as mesmas em atos efetivos que proporcionem a construção de um mundo melhor ${ }^{19}$.

19

Deste modo e não descurando a reflexão sobre o desenvolvimento social, pensamos, ser por intermédio da conjugação de políticas económicas e sociais que mais facilmente se poderá perspetivar o desenvolvimento local, podendo os assistentes sociais - dada a posição privilegiada que ocupam - desempenhar um papel de extrema importância em todo este processo. Nomeadamente no que concerne, de acordo com James Midgley (1996) (i) à «mobilização do capital humano», por intermédio de investimentos ao nível dos cuidados de saúde, educação, entre outros, em paralelo com a mobilização da população na sua própria promoção; (ii) ao «estimular a criação de capital social», podendo esta, assumir uma via materialista (criação de infraestruturas económico-sociais, tais como, estradas, pontes, saneamentos, eletricidade...), ou uma via idealista (valorização da identidade comunitária) que propugne o aparecimento de fortes relações de cooperação conducentes ao desenvolvimento de atividades económicas produtivas; (iii) facilitar a integração de grupos de baixos recursos, por intermédio da formação profissional 
Assim sendo, a adoção desta perspetiva pelo serviço social, poderá propugnar uma alteração da imagem da profissão, porque, a prática ao contribuir - em conjugação com outras profissões - para a integração ativa na sociedade de cidadãos anteriormente excluídos e dependentes de recursos públicos, deixará de ser primordialmente conotada com a atribuição de subsídios, aproximando-se de uma prática que ao priorizar o trabalho em conjunto com aqueles que se encontram nas margens poderá facilitar a esses mesmos indivíduos o alcance da cidadania, tanto enquanto status, como enquanto prática, ou seja, contribuindo para a promoção da cidadania ativa.

orientada para a readaptação a novos postos de trabalho e ou para a criação de autoemprego (individual, familiar ou em cooperativas). 


\section{REFERÊNCIAS BIBLIOGRÁFICAS}

ANDERSON, P. (1995). Balanço do Neoliberalismo. In Pós Neoliberalismo: As Políticas Sociais e o Estado Democrático. Brasil, Paz e Terra, p. 9-23,

ARENDT, H. (1983). A Condição Humana. Rio de Janeiro, Forense Universidade, $338 \mathrm{pp}, 1958$.

BEYME, K. (1996). Citizenship and the European Union. In Social and Political Citizenship in a World of Migration - Conference, European Forum. Florence, European University Institute, policopiado, $27 \mathrm{pp}$. .

BOTTOMORE, T. (1992). Citizenship and Social Class, Forty Years On. In MARSHALL, T. H.; BOTTOMORE, Tom. Citizenship and Social Class. Londres, Pluto Press, p. 55-93.

CALAME, P. (1995). La Citoyenneté en Europe. In Citoyenneté Sociale, Citoyenneté Locale: Expériences in Europe, Territoires, $\mathrm{n}{ }^{\circ}$ 354. Paris, ADELS, p. 18-23.

CANOTILHO, G. (1995). Direito Constitucional. Coimbra, Livraria Almedina,.

CASTEL, Robert. (1994). La Precarité: Transformations Historiques et Traitement Social. In SOULET, Marc-Henry (dir.). De la NonIntegration Essais de Définition Théorique d'un Problèm Social Contemporain. Fribourg, Ed. Universitaires Fribourg, p. 11-25,.

CROUCH, C. (1996). Social and Economic Citizenship below the Nation State. In Social and Political Citizenship in a World of Migration - Conference, European Forum. Florence, European University Institute, policopiado, $15 \mathrm{pp}$.

DELARUE, J-M. (1991). Citoyenneté Oubliée, Citoyenneté Obligée. Un des Moteurs de la Gestion Urbaine. In Renouvelons la Citoyenneté. Territoires, n. $^{\circ}$ 321. Paris, ADELS, p. 15-27.

EDER, Klaus, (1996). Social Movement Organizations as a Democratic Challenge to Institutional Politics? And What Does this Have to Do with Political Citizenship. In Social and Political Citizenship in a World of Migration - Conference, European Forum. Florence, European University Institute, policopiado, $23 \mathrm{pp}$.

FABRICANT, M.; BURGHARDT, S. (1992). The Welfare State Crisis and the Transformation of Social Service Work. New York, M. E. Sharpe, $258 \mathrm{pp}$. 
FRIEDMANN, J. (1996). Empowerment. Uma Política de Desenvolvimento Alternativo. Oeiras, Celta Editora, 197 pp., 1992.

GONTCHAROFF, G. (1991). Les Déficits de Démocratie. Education et Civisme. In Renouvelons la Citoyenneté. Territoires, $\mathrm{n}^{\circ}$ 321. Paris, ADELS, p. 55-56.

HABERMAS, J. (1994). Citizenship and National Identity. In STEENBERGEN, Bart van (ed). The Condition of Citizenship. London, Sage, p. 20-35,.

HÉRITIER, P. (1995). La Citoyenneté: un Gadget?. In Expériences en Europe - Citoyenneté Sociale, Citoyenneté Locale. Territoires, n. ${ }^{\circ}$ 354. Paris, ADELS, p. 26-27,.

IAMAMOTO, M. (1995). A Formação Social na Contemporaneidade: Dilemas e Perspectivas. Rio de Janeiro, Policopiado, 30 pp..

JENSON, J. (1996). Citizenship Regimes: From Equity to Marketisation. In Social and Political Citizenship in a World of Migration - Conference, European Forum. Florence, European University Institute, policopiado, $37 \mathrm{pp}$..

KAZEPOV, Y. (1996). Social Exclusion and Citizenship Systems: The Institutional Structuring of Poverty. In Social and Political Citizenship in a World of Migration - Conference, European Forum. Florença, European University Institute, policopiado, $18 \mathrm{pp}$.

MARSHALL, T. H.. (1950). Citizenship and Social Class. In MARSHALL, T. H.; BOTTOMORE, Tom. Citizenship and Social Class. London, Pluto Press (1992), p. 3-51.

MENEZES, M. (1999). As Comunidades Imigrantes em Portugal. In Intervenção Social, n. ${ }^{\circ}$ 20. Lisboa, ISSSL, p. 133-150,.

MENEZES, M. (2001). As Práticas de Cidadania num Poder Local Comprometido com a Comunidade. Coimbra, Editora Quarteto, 128 pp.

MIDGLEY, J. (1996). Social Work and Economic Development. In International Social Work, vol. 1, n. ${ }^{\circ}$ 39. London, Sage Publications, p. 5-25.

MIRANDA, JA. (1994). Bragança. A Ideia de Política. Lisboa, Culturgest, policopiado, $11 \mathrm{pp}$.

MISHRA, R. (1995). O Estado-Providência na Sociedade Capitalista. Estudo Comparativo das Políticas Públicas na Europa, América do Norte e a Austrália. Lisboa, Celta Editora, 132 pp., 1990.

MONDOLFO, P. (1997). Repenser L`action Sociale. Paris, Dunod, 216 pp. 
NETTO, J P. (1994). Crise Global Contemporânea e Barbárie. In Intervenção Social, n. ${ }^{\circ}$ 9. Lisboa, ISSSL, p. 63-79.

PAPADOPOULOS, Y. (1996). Direct Democracy: Empowering the Citizen? The "Broken Promises" of Democratization. In Social and Political Citizenship in a World of Migration - Conference, European Forum. Florence, European University Institute, policopiado, $19 \mathrm{pp}$.

QUELOZ, N. (1994). La Non-Integration, un Concept Qui Renvoie Fondamentalement à la Question de la Cohésion et de L'ordre Sociaux. In SOULET, Marc-Henry (dir.). De la Non-Integration Essais de Définition Théorique d`un Problèm Social Contemporain. Fribourg, Ed. Universitaires Fribourg, p. 151-163.

ROBERT, F. (1991). Education et Civisme. Pédagogie du Civisme pour non Citoyen. In Renouvelons la Citoyenneté. Territoires, n. 321. Paris, ADELS, p. 45-49.

ROCHE, M. (1996). Rethinking Citizenship. Welfare, Ideology and Change in Modern Society. Cambridge, Polity Press, 280 pp., 1992.

ROSANVALLON, P. (1995). La Nouvelle Question Sociale. Repenser L'État-Providence. Paris, Sevil, 223 pp..

SILVA, M O. da Silva e (1992). A Crise dos Projectos de Transformação Social e a Prática Profissional do Serviço Social. In Revista Serviço Social \& Sociedade, n. ${ }^{\circ}$ 40. São Paulo, Cortez Editora, p. 101-117.

SHKLAR, J. (1991). La Citoyenneté Américaine. La Quête de L'Intégration. Calmann-Lévy, $146 \mathrm{pp}$.

SHKLAR, J. (1995). Justice et Citoyenneté. In Pluralisme et Équité, La Justice Sociale dans les Démocraties. Paris, Éditions Esprit, p. 85102.

SOULET, M-H. (1996). Crise do Estado Providência e Recomposição da Intervenção Social. In Intervenção Social, n. ${ }^{\circ}$ 13/14. Lisboa, ISSSL, p. 107-125.

SOULET, M-H. (1997). Les Rapports Entre Solidarité Publique et Solidarités Privées: Vases Communicants ou Coopération Conflictuelle? In Forum Les Cuvres d'Entraide en Question. Neuchâtel - Caritas et Institut de Sociologie de l'Université de Neuchâtel, 20 pp., policopiado.

SOULET, M-H. (s.d.). Social Emergency: Between Myth and Reality. Policopiado, $17 \mathrm{pp}$.

SPOSATI, A. (1997). Mínimos Sociais e Seguridade Social. In Serviço Social \& Sociedade, n. ${ }^{\circ}$ 55. São Paulo, Cortez Ed., p. 9-38. 
TELES, V. (1994). Sociedade Civil e a Construção de Espaços Públicos. In Anos 90. Política e Sociedade. São Paulo, Editora Brasiliense, p. 91-102.

WALZER, M. (1977). Das Obrigações Políticas. Ensaios Sobre Desobediência, Guerra e Cidadania. Rio de Janeiro, Zahar Editores, 1975.

WALZER, M. (1993). As Esferas de la Justicia. Una defensa del Pluralismo y la Igualdad. México, Fondo de Cultura Económica, 1983.

WIENER, Antje (1996). Making Sense of the New Geography of Citizenship - Fragmented Citizenship in the European Union. In Social and Political Citizenship in a World of Migration Conference, European Forum. Florença, European University Institute, policopiado, $40 \mathrm{pp}$. 